\title{
“EN MEDIO DE UN RINCONZILLO”. ARGUMENTOS PARA LA AMPLIACIÓN JURISDICCIONAL DE LA AUDIENCIA DE CHARCAS A TRAVÉS DE LA COMUNICACIÓN POLÍTICA ENVIADA A LA CORONA (1561-1563)
}

\author{
“EN MEDIO DE UN RINCONZILLO”. ARGUMENTS TO THE JURISDICTIONAL \\ EXTENSION OF THE AUDIENCIA DE CHARCAS THROUGH THE POLITICAL \\ COMMUNICATION SENT TO THE CROWN (1561-1563)
}

Sergio H. Angeli*

\begin{abstract}
El presente trabajo es una primera aproximación a la comunicación política entre la jurisdicción de la Audiencia de Charcas y la Corona castellana mediante el denominado "factor distancia". Tomaremos como objeto de análisis la comunicación epistolar que realizó la Real Audiencia y Chancillería de La Plata con la católica majestad. En esta oportunidad solo analizaremos las misivas que la institución de justicia escribiera hacia la metrópoli como cuerpo colegiado. Temporalmente se estudiarán las comunicaciones enviadas por el tribunal de justicia entre los años 1561 y 1563.
\end{abstract}

Palabras claves: Audiencia, Charcas, oidores, Corona, comunicación política.

The present work is a first approach to political communication between the jurisdiction of the Audiencia de Charcas and the Castilian crown through the so-called "distance factor". We will take as an object of analysis the epistolary communication made by the Real Audiencia y Chancillería of La Plata with the Catholic Majesty. This time we will only analyze the missives that the justice institution wrote to the metropolis as a collegiate body. Temporarily, we studied the communications sent by the court of justice between the years 1561 and 1563.

Key words: Audiencia, Charcas, oidores, Crown, political communications.

\section{Introducción}

El presente trabajo es una primera aproximación a la comunicación política entre la jurisdicción de la Audiencia de Charcas y la Corona castellana mediante el denominado "factor distancia". Desde hace varios años, la distancia entre los territorios ultramarinos y la metrópoli peninsular es utilizada como un recurso analítico para comprender mejor de qué manera se gobernó una monarquía tan vasta y fragmentada como la castellana durante los siglos XVI al XVIII (Barriera, 2013; Gaudin, 2017a; Gaudin 2019).

Tomaremos como objeto de análisis la comunicación epistolar que realizó la Real Audiencia y Chancillería de La Plata con la católica majestad. En esta oportunidad solo analizaremos las misivas que la institución de justicia escribiera hacia la metrópoli como cuerpo colegiado. Dejaremos fuera de análisis la correspondencia particular de los oidores con las autoridades residentes en Castilla para otros abordajes.

La Audiencia de Charcas fue creada por Real Cédula del rey Felipe II el 4 de septiembre de 1559, pero comenzó sus labores de administrar justicia en 1561 con la llegada de sus cuatro primeros magistrados, los oidores Pedro Ramírez de Quiñones (a la sazón presidente del tribunal), Juan de Matienzo, Antonio López de Haro y Martín Pérez de Recalde, a la villa de La Plata, sede del tribunal y cabecera de la región.

La villa de La Plata fue fundada por el conquistador castellano don Pedro de Anzurez, marqués de Camporredondo. La fecha de fundación sigue siendo discutida por historiadores e investigadores debido a la ausencia de las actas del cabildo platense, las que nunca fueron encontradas en ningún repositorio, ni americano ni peninsular. Para algunos académicos, la fundación se realizó el 29 de septiembre de 1538 , mientras que para otros se produjo el 16 de

\footnotetext{
* CONICET-Instituto Ravignani, Instituto de Historia del Derecho (INHIDE), Universidad de Buenos Aires. Dirección postal 25 de Mayo 217. Ciudad Autónoma de Buenos Aires, Argentina. Correo electrónico: sh.angeli@ gmail.com
} 
abril de 1540 (Abecia 1939; Mendoza Loza 1938). Las casi dos décadas que separan la fundación del establecimiento de la Audiencia estuvieron signadas por la anarquía provocada por las Guerras Civiles (1538-1554) y la puesta en marcha del complejo extractivo, agrícola y ganadero surgido al calor de los descubrimientos de Porco (1538) y Potosí (1545). Temporalmente se estudian las comunicaciones enviadas por el tribunal de justicia entre los años 1561 y 1563, cuando Felipe II estableció los límites definitivos de la Audiencia charqueña. Es nuestra intención poder comprender de qué manera se fue generando lo que Peter Bakwell (1988) denominó acertadamente "la maduración del gobierno real en el Perú". Fueron aquellos años, anteriores a la llegada del virrey don Francisco de Toledo (1569), en los que la Audiencia de Charcas buscará dar información a la monarquía católica del estado de la tierra, los sucesos que allí acontecían entre españoles e indígenas, y las posibles medidas a desarrollar para consolidar la región en beneficio, tanto de la Corona como del bien común local.

\section{Una ciudad y su Audiencia en la distancia}

Ubicada a $2.900 \mathrm{msnm}$, la ciudad de los cuatro nombres, La Plata, Chuquisaca, Charcas o Sucre, está enclavada en unos templados valles mesotérmicos que hacen de aquel área un lugar propicio para la vida humana, el cultivo y pastoreo de diversas especies.

Pasadas las primeras décadas de humilde asentamiento, y sobre todo luego del descubrimiento y puesta en explotación de Potosí a partir de 1545, la ciudad de La Plata comenzará a ser asiento de ricos encomenderos, mineros, mercaderes, letrados y religiosos, que ennoblecerán la urbe y la posicionarán en un lugar clave y de renombre en el sur andino.

La instalación de la Real Audiencia de Charcas fue un acontecimiento icónico para la "muy noble y leal" ciudad, como la bautizara el emperador Carlos $\mathrm{V}$ cuando le otorgó sus nuevas preeminencias y su escudo de armas en 1555 a la anteriormente villa de La Plata. A partir de 1561, y con la entrada del Sello Real, la decana población de los Andes Meridionales se transformó también en corte. Esto fue posible, ya que las Reales Audiencias y Chancillerías eran la monarquía misma, por un proceso de clonación simbólico (Clavero 1996) en donde el monarca se hacía presente en el artefacto del sello, con el que contaban los magistrados y era custodiado por el chanciller del tribunal (Gómez Gómez 2008).
El enorme peso simbólico de la Audiencia, sumado a la residencia de los vecinos encomenderos, mercaderes regionales y mineros potosinos, convirtió a este núcleo poblacional en objeto de sumo interés para la Corona castellana. Quienes residieron en La Plata demostraron, a la comarca y las áreas circundantes, su magnificencia. $\mathrm{La}$ arquitectura de la ciudad se erigió como símbolo de aquel poder regional. Como bien señala Ana María Presta (1990), el espacio es una traducción simbólica y material que debe contextualizarse e interpretarse. La autora destaca cómo:

las casas de los españoles eran fuertes, de adobe, de uno o dos pisos, cubiertas de tejas y ostentando maderas de cedro, tipa, quinaquina y soto labradas finamente. Los portales, marcos de ventanas y esquinas se hacían en ladrillo e imitando la arquitectura clásica, jónica o corintia, luciendo balcones y rejas de hierro o madera. Las torres, galerías y jardines eran patrimonio de los mejor situados, mientras que las casas de las autoridades indígenas guardaban un patrón similar, mostrando fuentes y jardines (Presta 1990).

La transformación de la ciudad en corte, y el intento de emular el habitus cortesano metropolitano, también se reflejó al interior de las viviendas y en las abultadas sumas que sus propietarios gastaban en ellas. Fue así que,

el adorno de sus casas, salas, cuadras, estrados y cama es de mucho precio, porque las adornan de ricas colgaduras, de telas, terciopelos, damascos, brocateles, tafetanes, listados, paños de corte finos, de a dos, tres y cuatro mil pesos de precio, de alfombras preciosísimas, persianas y turquescas, valor de mil pesos, más y menos, de muchos cojines de terciopelo de dos haces, con guarniciones de oro, de sillas de vaqueta de Moscovia, taburetes de terciopelo, escritorios costosísimos de Alemania de ébano y marfil y carey, de bufetes de plata, cazolejas, perfumadores y braseros, pinturas excelentísimas de España y Roma, en láminas, tablas y lienzos, y de pintores de esta tierra que los hay muy buenos; de manera que en estas y otras curiosidades 
del menaje de casa, hay personas que tienen veinte y treinta mil pesos, más y menos (Ramírez del Águila, 55).

El destacado lugar que fue configurando la urbe platense y sus habitantes la convirtieron en un importante centro de poder regional que compitió, tanto simbólica como fácticamente, con Cuzco y la propia Lima. Esta competencia se verá reflejada en las constantes disputas que sucederán entre el tribunal limeño, otrora el único con competencias judiciales en segunda instancia, y el charqueño. La reticencia de la Audiencia de Lima a la erección de la Audiencia de Charcas se materializó muy tempranamente, cuando los oidores limeños, junto con el virrey conde de Nieva, le adjudicaron al novel tribunal platense únicamente 100 leguas de jurisdicción en rededor del casco urbano. Las quejas constantes de los magistrados de Charcas al rey hicieron que Felipe II emitiera una Real Cédula el 29 de agosto de 1563, ampliando el área de actuación de la Chancillería chuquisaqueña (Morales 2013: 15). De esta forma, siguiendo los postulados de Antonio Manuel Hespanha (1993), el espacio fue producto de una práctica social y simbólica. La "división política del espacio es también un instrumento de poder" (Hespanha 1993: 88), que se utilizó para afianzar a ciertos grupos sociales en detrimento de otros. La configuración plural del espacio, quebrando los paradigmas de centros omnipotentes y subsumidas periferias, revaloriza la lucha constante en diferentes niveles para consolidar diversas corporaciones en múltiples territorios que se reconfiguraban constantemente. Es así como la miniaturización del espacio conllevó a que la superioridad jurisdiccional del monarca consistiera "únicamente en un poder de control o de armonización del ejercicio de los poderes inferiores $[\ldots]$ los dominios jurisdiccionales de estos poderes inferiores mantenían su autonomía (y de aquí podían expresarse territorialmente de un modo también autónomo)" (Hespanha 1993: 100). Pensar de esta manera los espacios de la monarquía católica en el orbe indiano permite comprender mejor las disputas jurisdiccionales de los múltiples polos poblacionales y las estrategias que llevaron adelante los titulares de dichos poderes.

Los utillajes mentales que derivaban del pasado medieval y su relectura moderna, ubicaban la frase del Derecho Común iurisdictio cohaeret territorium (la jurisdicción es coherente con el territorio) en la cúspide de estas disputas jurisdiccionales. La rigidez y la indisponibilidad del territorio fueron la clave para pensar entonces la organización políticaadministrativa del espacio (Hespanha 1993: 101). Se llevó adelante un proceso de territorialización "que consiste ni más ni menos en la conversión de las tierras (como entidad geográfica) en territorios (como entidad política)" (Garriga, 2006). Este proceso, como bien lo recalca Carlos Garriga, nació de la propia cultura jurisdiccional que se desarrollaba desde hacía centurias en Europa. No provenía de una creación arbitraria ex nihilo, sino que hundía sus raíces en un extenso pensamiento político que se afianzó a partir del ius commune en Castilla y fue trasladado hacia el resto de los territorios ultramarinos. Fueron criterios que se consideraban indisponibles en aquella tradición jurídica que todo lo empapaba. Dos exigencias básicas tenía, "el pluralismo institucional, que era resultado directo de la concepción corporativa de la sociedad, para la resulta perentoria de la reducción de las gentes a ciudades, como repúblicas dotadas de poder; y la construcción de un aparato de magistrados apto para la realización de la justicia (esto es, para mantener a cada uno en su derecho)" (Garriga, 2006).

Se configuró por tanto una monarquía de repúblicas (Herrero Sánchez 2017) que, por medio de los procesos de agregación, ampliaron territorialmente la Península en los siglos XV y XVI (Xil Pujol 2016: 70). Las Reales Audiencias cumplieron una función clave a lo largo de todas las tierras que se fueron descubriendo y poblando. Como ya se mencionó, el Sello Real hacía presente al rey ausente en la distancia, de allí los innumerables protocolos y ceremonias que requerían su recibimiento y custodia (Gómez Gómez 2008). La instalación de las Audiencias generó un patrón de uniformidad al fragmentado espacio indiano. El "dominio regio se entiende en términos jurisdiccionales y se corporiza en los tribunales que actúan mediante el sello real, entonces no caben territorios vacíos de audiencias" (Garriga 2006).

La llegada del gobernador Lope García de Castro en 1564 fue el comienzo para afianzar a la monarquía católica en los territorios peruanos. El nuevo gobernador, que también fue nombrado presidente de la Audiencia de Lima y justicia mayor, por el fallecimiento del virrey conde de Nieva, comenzó una tarea necesaria a la administración virreinal: reducir sensiblemente el poder de los encomenderos, los frailes y los curacas. Asentó las bases de su gobernación destacando, para espacios 
específicos, en una suerte de ensayo de gobierno, los nuevos corregidores de indios, las reducciones de los disgregados ayllus y la puesta en marcha de las resoluciones del Concilio de Trento, favoreciendo al clero secular por sobre el regular. Las nuevas Audiencias de Quito (1563) y de Concepción (1567) cimentaron cortes jurisdiccionales que hacían presentes al rey ausente y consolidaban así su poder in situ.

\section{Informar el proceso de territorialización}

Una vez que las tierras conquistadas y pobladas pasaron a ser territorios de la monarquía, con sus entramados administrativos e institucionales, se desarrolló un nutrido sistema de comunicación por el que la Metrópoli buscaba estar informada de los sucesos de sus espacios ultramarinos. El Perú se convirtió, hacia mediados del siglo XVI, no solo en un lugar de enormes riquezas por la explotación de las minas de plata, sino también en una de las partes más alejadas de la corte peninsular. El emperador Carlos V había sufrido las intestinas guerras civiles entre almagristas y pizarristas, la anarquía del espacio peruano por parte de Gonzalo Pizarro entre 1544 y 1548, y los sucesivos levantamientos de los disconformes encomenderos liderados por Francisco Hernández Girón en 1553 y 1554. Pese a que muy tempranamente se sancionaron leyes para que los nuevos colonos enviaran todo tipo de misivas informativas a la Corona, el resultado no parecía ser el adecuado. Para una monarquía que cifraba en la justicia la virtud de su gobierno, la instalación de Reales Audiencias se convirtió en un factor clave del poder real. Gobernar era hacer justicia, como lo remarcó Bartolomé Clavero (1996), cifrando en los tribunales audienciales la confianza necesaria para estabilizar los espacios indianos. Incardinadas en las sedes de sus distritos, las Audiencias se convirtieron, no solo en tribunales de justicia, sino también en instituciones claves para mantener informada a la monarquía acerca de los sucesos que acontecían en las Américas. Las Chancillerías americanas generaron una significativa cantidad de cartas, memoriales e informes varios, que acrecentaron en el Consejo de Indias los escritorios de los diferentes consejeros con variopintas informaciones de lo que sucedía allende el Atlántico. Imposibilitados de estar físicamente en los extensos territorios que se iban incorporando, los consejeros de Indias necesitaban cada vez más de las informaciones procedentes de los distritos audienciales, digerirlas y sintetizar las que ponderaban valiosas para el conocimiento del soberano y sus secretarios más cercanos. Aunque todo aquel que quisiera podía escribir a la Corona, lo cierto es que pocos tenían la capacidad de hacerlo. La escritura estaba circunscripta a un reducido número de agentes de pluma que habían logrado alfabetizarse, lo que sumado al costo del papel y del correo marítimo, generó que muchas veces "la información circulaba $[\ldots]$ por canales estrechos y unívocos" (Gaudin 2020). Las Audiencias, al ser la monarquía misma en las Indias, debían cumplir entonces la tarea de informar al rey y sus Consejos lo más fidedignamente posible de lo que estaba sucediendo.

La ciudad de La Plata se encuentra a $417 \mathrm{~km}$ de la de Nuestra Señora de La Paz, a 945 km del Cuzco, a 1.485 de Lima y a 9.182 de Madrid (medidos siempre en línea recta, lo que no da cuenta de las enormes dificultades de transitar un territorio escarpado y casi incomunicado por montañas, quebradas y un inhóspito altiplano). Sin dudas, semejantes distancias implicaban un factor de riesgo tan importante como los ataques de los corsarios a las flotas y galeones, los levantamientos de encomenderos o de indígenas, en cuanto al traslado de la información manuscrita por los correos reales se refiere. Mantener una comunicación política constante con la Península fue muchas veces más una aspiración que una realidad.

Hacia 1561, momento en que comenzó a sesionar la Audiencia de Charcas, coexistían en la urbe platense tres importantes instituciones jurisdiccionales. El cabildo y sus regidores, que representaban al poder municipal; la Audiencia y sus magistrados, que encarnaban a la monarquía ausente; y el obispado con su cabildo catedralicio, que estructuraban el poder eclesial sobre todas las almas del territorio. La muy noble y leal ciudad de La Plata conformaba un intrincado espacio jurisdiccional en donde los divergentes poderes establecidos se enfrentaban jurisdiccionalmente cada vez que podían. Contar con una información rápida y certera de lo que acontecía era crucial para mantener equilibrado el dominio de la monarquía en aquellas distantes tierras.

"Yo quiero ser informado", reclamaba enfáticamente el emperador Carlos V en una Real Cédula del 9 de noviembre de 1526 (Brendecke 2012: 274). La información que se necesitaba para el gobierno del Nuevo Mundo no era lo suficientemente precisa para 
que la corte y el Consejo de Indias pudieran tomar decisiones concretas sobre los asuntos indianos. A partir de ese momento, se llevó adelante una serie de ingentes esfuerzos para comenzar a recabar la mayor información posible de las posesiones ultramarinas. Una enorme voluntad por saber qué acontecía insufló al recientemente creado Consejo de Indias (1524). Actuar políticamente requería de información confiable, tanto de las nuevas tierras descubiertas como de los hombres y las instituciones paulatinamente instalados en las posesiones de ultramar.

Como ya hemos advertido, las Audiencias se irían convirtiendo en un nodo central de la información al monarca. En 1533, el emperador Carlos V, nuevamente, envió a la Audiencia y Chancillería de Nueva España una cédula en donde reclamaba:

tener entera noticia de las cosas de essa tierra y calidades dellas, vos mando que $[\ldots]$ hagays hazer una muy larga y particular relación de la grandeza de esa tierra, ansi de ancho como de largo, y de sus límites, poniéndolos muy específicamente por sus nombres propios, y como se confina y amojona por ellos, y ansi mismo de las calidades y extrañezas que en ellas ay, particularizando las de cada pueblo por sí, y que poblaciones de gentes ay en ella de los naturales, poniendo sus ritos y costumbres particularmente, $\mathrm{y}$ ansi mismo que vezinos y moradores Españoles ay en ella y donde vive cada uno [...] y que puertos y ríos tienen, y que edificios ay hechos, $\mathrm{y}$ que animales y aves se crian en ella, y de que calidad son (Brendecke 2012: 283).

El mapa del imperio, parafraseando el cuento borgiano, debía comenzar a rellenarse con datos concretos. La política de implantación de las Audiencias, en conjunto con el proceso de territorialización antes descripto, iba en ese sentido. Sobre todo porque recabar información no era un acto meramente estadístico. La Corona utilizaba los datos aportados por una multiplicidad de agentes para armar el enorme rompecabezas político que se empezaba a estructurar. Las representaciones, que los consejeros y el monarca poseían de las Indias, "constituyen una construcción política y cultural que tiende a reificar el espacio imperial" (Gaudin 2017b: 29). Se volvió acuciante, sobre todo en las díscolas tierras peruanas, aceitar el poder de la monarquía por vía de la justicia, representada en sus máximos tribunales, pero también por medio del conocimiento de sus territorios, ya que "sirve para circunscribir la envergadura del poder, medir su alcance e intentar conservarlo por todos los medios" (Gaudin 2017b: 31).

\section{Las misivas del tribunal al rey}

Las cartas, memoriales e informes que las Audiencias enviaban al rey o al Consejo de Indias iban firmadas por todos sus ministros y cubrían amplios temas de la jurisdicción en la que el tribunal desarrollaba sus funciones. En algunas misivas se trataban diferentes asuntos y en otras solo se informaba acerca de un caso en particular. De todas ellas, fueran cortas o extensas, se podían inferir datos sumamente útiles para la Corona. Sería interesante poder saber ¿Quiénes elegían los temas a tratar? ¿Cómo se ponían de acuerdo los magistrados en los datos informados? ¿De qué manera se saldaban las diferencias que guardaban entre ellos y se evidenciaban en las visitas al tribunal? ¿Habría incidencia de los notables vecinos en la selección de los temas? Todas estas dudas, y tantas otras, darían cuenta del parecer intrínseco que, como cuerpo colegiado, tuvieron los oidores. En nuestro caso particular de análisis sería sugerente saber cómo convivieron, en la redacción de estas epístolas, personalidades tan fuertes en sus opiniones como los licenciados Juan de Matienzo y Martín Pérez de Recalde, enemistados ambos casi desde un primer momento. O cómo hizo el presidente del tribunal, el licenciado Pedro Ramírez de Quiñones, para apaciguar las diferencias internas de criterio de cada uno de sus compañeros de curul. Interrogantes que nos develarían la vida interna del tribunal y nos darían una mayor certeza de la dinámica cotidiana de estos hombres de toga que, reunidos en Real Acuerdo y con el Sello Real presente, se convertían en la personificación de la mismísima monarquía en Indias.

Desde su fundación en 1561, la Audiencia de Charcas mantuvo una fluida correspondencia con la corte de Felipe II. Entre los muchos asuntos que en ellas se destacan, podemos nombrar, como los más salientes, los relativos a la Real Hacienda y sus oficiales, el estado de la tierra, los cuidados que se debían hacer a las comunidades de indios, las enfermedades que azotaron la región, la necesidad de construir puentes y obras de infraestructura, las disputas entre los conquistadores españoles y las 
nuevas expediciones de conquista, los problemas relacionados con la caja de bienes de difuntos, los alzamientos de los indios Chiriguanos y Diaguitas en los confines audienciales, el recibimiento de las cédulas reales y los constantes enfrentamientos entre el tribunal de La Plata con el virrey y la Audiencia de Lima por los límites y las facultades de gobierno dentro de la jurisdicción. En todas las misivas, los oidores aportaron datos muy relevantes a la monarquía, para que esta, desde la Península, pudiera hacerse una idea más cabal de lo que ocurría en los distantes territorios charqueños.

Analizaré algunas informaciones enviadas al rey por parte de la Audiencia charqueña entre 1561 y 1563 , para tratar de entender de qué manera la corte peninsular pudo leer sus cartas y acercarnos a las posibles intenciones prácticas emanadas de los magistrados.

La magnífica recopilación de cartas y pareceres de nuestra Audiencia que efectuara Roberto Levillier constituyen la base de esta meditada investigación y la fuente de las reflexiones surgidas al calor de las misivas de los oidores (Levillier 1918-1922). A poco más de un mes de haberse asentado el tribunal en la ciudad de La Plata, el 22 de octubre de 1561, los miembros de la Audiencia de Charcas expusieron a Felipe II sus discrepancias por el escueto radio de apenas 100 leguas de extensión y actuación que le habían conferido el virrey conde de Nieva y los Comisarios de la Perpetuidad. En el extenso informe, dieron cuenta de un conocimiento geopolítico extraordinario de toda la jurisdicción. En su traslado desde la ciudad de Lima hacia La Plata, los magistrados tomaron caminos diferentes con el fin de poder tener un entendimiento más acabado del territorio a gobernar, según informaron en el escrito. El licenciado Matienzo "vino por el camyno de Arequipa que es el de los llanos", mientras que el licenciado López de Haro lo hizo "por el Cuzco que es el de la sierra por donde antes avia venydo el rregente [Ramírez de Quiñones]". Esta opción, de tomar divergentes caminos, fue realizada "para que viéndolo todo por vista de ojos se pudiese hazer a vuestra magestad verdadera rrelacion de la dispusicion y temple de la tierra y de la distancia del camino por donde pudiese vuestra magestad colegir lo que convenía se diese por distrito a esta chancilleria" (Levillier 1918: 23). En este párrafo introductorio de la misiva enviada al rey, los letrados se estaban erigiendo como los verdaderos, y prácticamente únicos conocedores de la geografía surandina. Era una opción que les garantizaría, a futuro, convertirse en interlocutores válidos y confiables del distante territorio jurisdiccional.

En la misma misiva, unos párrafos más adelante, se especificó cómo, dentro de las 100 leguas, "entran solo dos ciudades de españoles, esta [La Plata] y la de La Paz, en que puede aver quarenta vezinos y pocos mas moradores y algunos pueblos de indios en que entran de la provincia de Chicuyto de siete que ay y lo demás todo despoblado" (Levillier 1918: 24). La información no es del todo precisa, pero sirve de justificativo a los oidores para reforzar la necesidad de ampliar el radio de actuación del tribunal. A renglón siguiente, se le recuerda al rey que "no oviese tanta desigualdad entre las dos audiencias deste rreyno antes es servido que en todo sean yguales ansi en el distrito como en todo lo demás", resaltando la frase "como lo signyfica y manda vuestra magestad" (Levillier 1918: 24). Aquí, la novel Chancillería platense intenta retóricamente equipararse al tribunal de Lima, su competidor jurisdiccional desde un primer momento. Saben los ministros charqueños que solo interpelando al monarca en sus deseos ("lo signyfica y manda su magestad") podrían quebrar el predominio simbólico que tenía el tribunal limeño luego de tantos años de preeminencia y actuación en el Perú. Buscaban también invalidar los informes que se remitían desde la capital virreinal, debido a que se habían confeccionado mediante terceros testigos y conocimiento indirecto del terreno, dando cuenta de que la ampliación de su jurisdicción correspondería realizarse ya que ellos conocían la tierra "por vista de ojos, que es mas cierta que todas las que por relación se pueden dar" (Levillier 1918: 24). Los letrados sabían que para la cultura jurídica del ius commune ningún testigo era más confiable que aquel que había visto y oído los sucesos, de allí la argumentación que recorrerá toda esta carta y las sucesivas, posicionándolos como los únicos y verdaderos sabedores "por vista" de lo que convenía a su recientemente creada Chancillería.

Los magistrados también creyeron importante remarcar el desequilibrio en la extensión territorial de ambas Audiencias, datos que le eran de relevancia al Consejo de Indias para seguir afinando el conocimiento local de los espacios que se iban poblando e institucionalizando.

"En todos los rreynos desta governaicion del Peru ay mill e quynyentas leguas de 
largo de las quales se dan a esta audienicia dozientas no mas las ciento de la una parte que es todo despoblado hacia Chyle y las otras ciento hasta el Cuzco pobladas de yndios excepto sola la ciudad de La Paz que es de españoles" (Levillier 1918: 24-25).

Frente a este exiguo territorio, la Audiencia de Lima continuaba teniendo una extensa área de influencia:

y a la audiencia de los Reyes le quedan myll e trezientas leguas de distrito la mejor tierra y mas poblada, de todas en que entra el rreyno de Tierra firme en que ay dos ciudades muy rricas y de mucho trato del nombre de Dios e de Panama, y otras algunas villas, entra la provincia de Veragua tierra bien rrica en que ay otras dos ciudades pobladas nuevamente una junto a la mar del sur otra junto a la del norte, entran las iudades de Quyto-San Miguel-Piura Truxillo-Chachapoyas-La Çarca-Guanuco-Lima-Guamanga-El CuzcoArequypa, y otros muchos pueblos que estan entre estos como son -Valladolid-CamoraGuayaquyl-Puerto Biejo-Santa Cañete y Ribera y otros muchos, entra la provincia de Chicuyto ecepto dos lugares della que son de yndios, entra el rreyno y provincia de Chile donde ay muchas y muy rricas ciudades, entra la provincia de Tucuman, Juries, y Diaguytas y el descubrimiento y poblacion de Nufro de Chaves (Levillier 1918: 25).

La desproporción era enorme y dejaba a la Audiencia de Charcas "en medio de un rrinconzillo", enfatizándose que "la gran desygualdad es cosa bien desproporcionada" (Levillier 1918: 25). La apelación a la desigualdad entre las jurisdicciones también fue un tópico recurrente, al que apeló la Audiencia de La Plata constantemente, recordando al rey que los tribunales debían, como todo cuerpo bien proporcionado, mantenerse en armonía.

Siguiendo con la información pertinente a su nueva jurisdicción, los letrados charqueños enfatizaron su ubicación serrana y su clima frío, como otra característica más a tener en cuenta para ampliar los límites que les había otorgado el conde de Nieva. Resaltaban los ministros que: resulta también yncomodidad muy grande e yntolerable desta división de distritos ansi para los naturales como para los españoles porque siendo Lima tierra caliente y ado jamas nyeva, yela, ni llueve, y el Cuzco Arequipa y Chile, tierras de Sierra y muy frías, de muy diverso y aun contrario temple, cosa contra rrazon parece darles por distrito a Lima y dexarlas de dar a esta audiencia, siendo todas Sierras y de un mismo temple (Levillier 1918: 26).

Sin declararlo abiertamente, esta justificación, que puede pasar inadvertida o pensarse como una buena voluntad de los oidores para la salvaguarda de los naturales de las tierras serranas, se anclaba en una Real Cédula que el emperador Carlos V había expedido el 28 de enero de 1541 y que luego sería recopilada. En ella se especificaba que "los indios de tierra fría no sean llevados a otra cuyo temple sea caliente, ni al contrario, aunque sea en la misma Provincia, porque esta diferencia es muy nociva a su salud, y vida, y los virreyes, gobernadores y justicias hagan sobre esto las ordenanzas necesarias" (Recopilación de Leyes de Indias, Ley XIII, Título I, Libro VI). Sin introducir la cédula, ni hacer referencia a ella, los magistrados daban cuenta de su amplio conocimiento de la legislación real. Este dato, que se colige de la lectura del documento a partir del conocimiento de la legislación, pone en sobre aviso a los historiadores y etnohistoriadores que se adentran en la lectura de los documentos administrativos o de justicia y los utilizan solamente como simples canteras de datos para dotarlos, muchas veces, con interpretaciones sociológicas contemporáneas sin basamento alguno en la compleja normatividad indiana de Antiguo Régimen. La lectura de la reglamentación real, y la riquísima variedad documental municipal que se generó por aquellos siglos, podrían dar un mayor entendimiento y sustento de quién escribe, qué se escribe y cómo se leían estas piezas informativas que fueron remitidas hacia la metrópoli con notable frecuencia e intensidad durante los largos siglos de la dominación castellana (Tau Anzoátegui, 1997).

Siguiendo la lectura atenta de la carta que los magistrados platenses enviaron al rey, podemos entrever un conflicto que en estas primeras décadas del gobierno peruano se mantenía aún latente. En las Leyes Nuevas de 1542, el emperador Carlos V estableció que los espacios de Nueva España y el 
Perú fueran gobernados por virreyes "que representen nuestra Real persona, y tengan el gobierno superior, hagan y administren justicia igualmente a todos nuestros súbditos y vasallos, y entiendan en todo lo que conviene al sosiego, quietud, ennoblecimiento y pacificación de aquellas Provincias" (Recopilación de Leyes de Indias, Ley I, Título III, Libro III). La decisión y puesta en marcha del gobierno por virreyes, en una cultura jurisdiccional que establecía a la justicia y sus tribunales como virtud cardinal de gobierno, trajo aparejados no pocos conflictos entre ambas autoridades. Gobierno y justicia no iban por vías separadas durante el Antiguo Régimen. Ya hemos puesto de manifiesto que gobernar es hacer justicia, y que el conocido tópico provenía de la creencia en que el rey es ante todo juez (Clavero 1996: 15). Las disputas jurisdiccionales entre los virreyes y las Audiencias tuvieron en las Indias un destacado análisis debido a la variedad y constancia de los enfrentamientos. En el escenario peruano, no se puede soslayar que el primer virrey del Perú, don Blasco Núñez Vela, fue apresado, enviado de regreso a Castilla y en el entretanto asesinado en el campo de batalla de Añaquito por orden de la misma Audiencia de Lima en complicidad con el levantisco Gonzalo Pizarro (Angeli 2012; Lohmann Villena 1977). La complejidad y la vastedad de estudios referentes a la figura del virrey escapan a este trabajo, pero la centralidad que van a tomar los nuevos alter ego del monarca, amerita una atenta lectura de la historiografía del tema que tienen en Manuel Rivero Rodríguez (2011) y su libro La edad de oro de los virreyes a su mejor expositor.

Si el primer virrey peruano había muerto en el campo de batalla, el segundo lo hará a los pocos meses de llegar a la sede virreinal. El longevo y destacado virrey de la Nueva España, don Antonio de Mendoza, intentó apuntalar la institución virreinal peruana, pero falleció en su intento por causas naturales en Lima en 1552. Tampoco tuvieron éxito en sus gobiernos los virreyes marqués de Cañete (1556-1560) y el conde de Nieva (fallecido en extrañas circunstancias en 1564). La preeminencia que obtuvo la Audiencia de Lima y sus magistrados en el gobierno interino del virreinato, elevaron a los letrados como una mejor opción de gobierno que la recientemente creada institución virreinal (Angeli, 2008). Atentos y sabedores que en la corte aún se debatía cuál sería la mejor forma de encauzar el gobierno del Perú, los oidores de Charcas propusieron e informaron:
Para que esto pudiese aver mejor efeto y la hazienda y patrimonyo rreal de vuestra magestad fuese aumentado y la tierra mejor governada y mas a contento de todo el rreyno y para la paz, sosiego y quyetud del y bien de los naturales podria vuestra magestad siendo dello servido dividir el govierno del Perú y su distrito en dos governaciones una en los llanos y otra en la sierra -los llanos govierne una audiencia y la sierra otra- en cada una aya seys oydores y un presidente letrado que juntamente con ellos tenga boto en justicia y gobernación (Levillier 1918: 26).

No era la primera vez, ni será la última, que el cuerpo colegiado de oidores arremetiera con la idea de que las Audiencias se hicieran cargo del gobierno y justicia de los territorios indianos. Menos es de extrañar si recordamos que los magistrados Juan de Matienzo, Antonio López de Haro y el regente Pedro Ramírez de Quiñones, iniciaron su viaje hacia La Plata desde la capital virreinal, en donde pasaron bastante tiempo con sus colegas limeños, y menos aún nos resulta extraño si entre ellos encontramos al Licenciado Matienzo, férreo propulsor de la idea de la preeminencia de los tribunales frente a los virreyes y cuyas disputas e influencia sobre alguno de ellos se patentizará en la década de 1570. Una vez más, este párrafo de la misiva ya citada del 22 de octubre de 1561 de los letrados charqueños, podría pasar desapercibido para un lector que ignorara los conflictos y las ideas de gobierno que se barajaban a mediados del siglo XVI. Pero para quién no pasaría inadvertido el consejo sería para el rey y sus colaboradores. Nos llama a la reflexión que mientras en Castilla se evaluaba qué medida se tomaría respecto del gobierno peruano, el sucesor del conde de Nieva, el licenciado Lope García de Castro, como ya advirtiéramos, fue enviado al Perú, en 1564, con los títulos de gobernador, justicia mayor y presidente de la Audiencia de Lima, mas no con el de virrey. Una lectura densa, como propone Cliffort Geertz (1973), de estas misivas letradas, nos puede aportar rica y esclarecedora información para comprender la cultura jurisdiccional que se iba territorializando más de lo que supondríamos. La católica majestad supo también leer estas informaciones en clave, no solo descriptiva, sino más bien política, las que aportaban para afinar los resortes de su dominio 
ultramarino en tierras tan necesarias económicamente para el sostén de una monarquía siempre al borde de la bancarrota.

Catorce días después de la misiva analizada anteriormente, el 5 de noviembre de 1561, el tribunal de Charcas volvió a escribirle al rey dando información de los sucesos e injerencia que sufría en su jurisdicción y pidiendo consejos acerca de cómo actuar. La distancia parecía favorecer los reclamos de la Audiencia de Charcas, la que está "al cabo del rreyno y en frontera de yndios advenedizos" (Levillier 1918: 38). El recurso de la lejanía, tan utilizado en la teoría política de la época, como recuerda Gaudin (2019), aquí se esgrime con claridad. Se enfatiza lo despoblado del área y el constante peregrinar hacia Lima por parte de los vecinos "no sirviendo sus vezindades como son obligados" (Levillier 1918: 38). Además, estos éxodos constantes hacia la capital virreinal insumían cuantiosas erogaciones que iban en detrimento del asentamiento y consolidación de una frontera tan necesaria económicamente para la Corona. Pero de algo debería estar seguro el rey, y es que "el rremedio que entendemos conviene [...] no se podrá poner desde lima que esta muy lexos para lo poder entender y rremediar" (Levillier 1918: 38). Al igual que en la carta del 22 de octubre, los oidores interpelaban la decisión real de crear el tribunal para la correcta administración de la justicia, recordándole al monarca "que para esto enbio vuestra magestad aquí esta audiencia" (Levillier 1918: 39). Pero sobre todo, ponen en aviso, que la gravedad radica en que "hacen nuevas leyes y ordenanzas y algunas corrigiendo y enmendando las que vuestra magestad tiene hechas con acuerdo de su rreal consejo de yndias" (Levillier 1918: 39). Pero lo que debería resultarle escandaloso a la monarquía era que, mientras se estaban haciendo ingentes esfuerzos para institucionalizar el Perú, desde Lima "se tratan de hazer otras [leyes] para las mynas, estando trecientas leguas dellas, sin las aver jamas visto por sola ynformacion de los que alla están, que pretenden su ynterese" (Levillier 1918: 39). Los oidores de la Audiencia de Charcas sabían perfectamente dónde y cómo radicar sus informes que, más que nada, eran advertencias. Mientras se estaba llevando adelante el proceso por la averiguación de la perpetuidad de las encomiendas (Goldwert 1956) y se buscaba poner fin a los intereses particulares de los grandes encomenderos que habían desestabilizado constantemente la región, el sutil, pero inteligente recordatorio respecto del tema, encendería las alertas del Consejo de Indias, principal opositor a la perpetuidad y a conceder privilegios a los beneméritos del Perú.

Pero, sobre todo, los ministros platenses volvieron a remarcar cómo los altos tribunales de justicias eran clones de la monarquía, y dejar que desde Lima se la subsumiera e ignorase como Chancillería en su distrito, generaría un aniquilamiento de la "autoridad dellas", degenerando en una posible anarquía como la que ya había sucedido, perdiéndose "la rreverencia que las deven y perdida se perderá sin duda todo" (Levillier 1918: 40). Ante los pedidos de los residentes para que la Audiencia los amparase en la justicia que tanto representaban "no se las damos, antes les entretenemos con palabras" (Levillier 1918: 39), haciendo notar cómo la función por excelencia de la monarquía quedaba trunca en la región. Pero a diferencia de los atropellos y las injerencias que realizaban la Chancillería limeña y el virrey, el tribunal de La Plata se mostraba ante el rey y sus consejeros como respetuosa de la legalidad y de las órdenes que se emitían desde la Península. Resaltaban, en la carta del 5 de noviembre, que "no avemos dado ny daremos lugar [a las injurias desde Lima], antes procuraremos sobre todo conservar la union que todos devemos tener, aunque se nos den ocasiones mas de las que cada dia se nos dan para no la tener" (Levillier 1918: 41). Sin dudarlo, la Audiencia de Charcas se mostraba ante la Corona como una institución apacible, conciliadora, respetuosa de lo que decidiera la corte y, sobre todo, conocedora de las necesidades del distrito. No es un dato menor recordar que por aquellos años la Audiencia de Lima estaba atravesando la visita del tribunal por la nepótica actuación de sus magistrados, que se reflejará en las duras sanciones que años posteriores recibirán del Consejo de Indias, luego de haber analizado los más de 70 cargos que se les confeccionaron a los ministros limeños por mal desempeño generalizado en sus oficios (Angeli 2013).

Tomemos un último ejemplo. En este caso, la carta enviada al rey el 1 de febrero de 1562 por los oidores Antonio López de Haro, Martín Pérez de Recalde y el regente Pedro Ramírez de Quiñonez. En ella los ministros expusieron a Felipe II los agravios que recibían del tribunal limeño y del virrey conde de Nieva. Comienza la misiva estableciendo, una vez más, las dimensiones de la jurisdicción y los argumentos por los que fueron enviados a ella: 
Por ser estos reynos del Pirú tan largos y aber tanta distancia de camino de unas partes a otras, y los vasallos de V.M. no fuesen mulestados yendo a pedir su justicia tressientas quinientas y ochocientas leguas y teniendo ellos entendido abia V. M. mandado fundar esta nueva Audiencia para la paz y sosiego de la tierra y para el bien de los naturales dello dando el authoridad y poder tan cumplido como nesesario hera para desagraviar a los querellosos pobres y miserables, y mayormente los naturales pudiesen alcanzar su justicia (Levillier 1918: 61).

El recurso argumental no cesaba de utilizarse en cada escrito. La insistencia generaba, que tanto el rey como el Consejo de Indias, no se olvidaran del asunto, que estuviera en agenda permanente, más sabiéndose que los temas del Perú por aquellos años eran de sumo interés para una Corona necesitada de constantes remesas de plata para hacer frente a sus enormes gastos europeos. Al final de cuentas, la Audiencia de Charcas quedaba a 18 leguas de Potosí y sus magistrados exponían un excepcional conocimiento del terreno y sus gentes.

Así como el argumento de la distancia era una desventaja para la Chancillería de Lima, por solo saber a partir de información de terceros sobre la jurisdicción de Charcas, la proximidad fue una ventaja para el tribunal chuquisaqueño en el gobierno de su distrito. La insistencia en la equiparación de todas las audiencias también volvía a emplearse en la pluma de los espabilados letrados. Siempre estaba presente el recordatorio para el mismísimo monarca que él había implementado dicha equiparación: "Vuestra Majestad fue servido declarar por su real cedula la ygualdad destas audiencias y dando a esta su real sello" (Levillier 1918: 63). El pequeño artefacto, con el que los magistrados sellaban sus sentencias, era una prueba irrefutable de la presencia viva del rey. Las acciones contrarias a los mandatos reales afectaban más al monarca en ausencia, que a los letrados en presencia. Y hacia allí se volvió a dirigir la hábil prosa del cuerpo togado en el escrito del 1 de febrero de 1562: "Porque en perjuicio suyo [...] embian probisiones libradas por el visorrey y comisarios de los corregimientos y otros officios de justicia que caen en el distrito desta audiencia sin que allamos visto los poderes que de V. M. para ello tienen" (Levillier 1918: 63). El resultado era más que claro, "con estas probisiones y semejantes nobedades se aniquilan las audiencias y la autoridad que V. M. les tiene dada" (Levillier 1918: 64). El descrédito ensombrecía más a la monarquía que al cuerpo de oidores. Si el intento de la Corona era robustecer su poder, influencia y sujeción del Perú, con el fin de que las remesas de plata fluyeran sin inconveniente hacia las arcas peninsulares, resultaba conveniente cimentar su autoridad afianzando a sus clónicos representantes en Charcas. Los letrados fueron muy versados en derecho, pero también muy hábiles en cómo informar a la corte, buscando que la lectura de sus escritos tuviera un impacto positivo a sus deseos y necesidades políticas territoriales que, a la vez y casi subliminalmente, resultasen en repensar las políticas del monarca.

A fin de cuentas, ellos no pretendían más que cumplir las ordenanzas regias para hacer justicia y acrecentar la Real Hacienda en provecho de su monarca. El pedido se mantenía incólume: "que se ampliase [la jurisdicción del tribunal] e fuese mas que el de las cinco leguas, y que en esta audiencia fuese hasta treinta, por que alcanzase los asientos de minas y nueba villa de Potosi que está diez y ocho leguas desta ciudad, por que desta manera se remediarían muchas cosas" (Levillier 1918: 72). Por ello "suplicamos a V.M. sea servida de aceptar nuestra boluntad en su serbisio" (Levillier 1918: 72), finalizaba el extenso escrito del 1 de febrero de 1562 .

\section{Consideraciones finales}

Luego de dos años de un intenso intercambio epistolar, la Corona tomó una determinación tajante acerca de la jurisdicción de la Audiencia de Charcas. Tanto el Consejo de Indias como el rey leyeron los pareceres del tribunal, las misivas que individualmente enviaban los oidores platenses, los informes del virrey conde de Nieva, los de los Comisarios de la Perpetuidad y los de la Chancillería limeña. Pero antes de refrendar la decisión pensada, enviaron a realizar una amplia averiguación en agosto de 1563 entre aquellos vecinos importantes del distrito en cuestión que estaban radicados en la corte luego de su estadía peruana. Con todo ese cúmulo monumental de diversidad de pareceres e intereses, el 29 de agosto de 1563, Felipe II firmó la definitiva Real Pragmática que establecía: "porque somos ynformados que estos [límites] fueron cortos, y que al nuestro servicio y buena gobernación de aquella tierra, conviene que la dicha audiencia 
de los Charcas se le den más límites que estos" (Levillier 1918: 588).

La batalla discursiva, que había colocado al nuevo tribunal de las Charcas en el epicentro de una constante comunicación política con el monarca católico y sus consejeros de Indias, obtuvo un resultado favorable a sus pedidos. Establecer una determinación desde la Península requería un sinfín de informes y conocimientos locales con los que la Corona no contaba en los primeros años del dominio metropolitano sobre su Nuevo Mundo. La tarea ciclópea de reconstruir escenarios, hasta ese momento completamente desconocidos por el mundo conocido, supuso el mayor flujo informativo que se recordara por aquellos años.

Los tópicos que utilizó la Audiencia de La Plata para su pedido, provenían de una riquísima tradición jurídica que abrevaba en el ius commune europeo. El conocimiento de la jurisdicción "por vista de ojos", ubicaba a los togados charqueños como a los verdaderos y prácticamente únicos testigos para declarar con certeza por aquel distante distrito de la monarquía. El resto de los actores políticos implicados en sostener las exiguas 100 leguas otorgadas a la Chancillería de Charcas solo pudo basar sus argumentos en informes secundarios de terceras personas, las que jamás habían llegado siquiera hasta el Cuzco. Se reforzaba el pedido en la necesidad de que todos los tribunales tuvieran un radio de actuación armónico, como establecía la tratadística de la época basada en la armonía de los cuerpos, la que además estaba refrendada por las cédulas que el rey remitía a los oidores y presidentes de Audiencias. Pero seguramente fue el finísimo conocimiento local que los letrados pudieron plasmar en cada una de las informaciones enviadas a Castilla, lo que terminó por primar en la decisión de la monarquía. Territorializar unas tierras que poco se conocían, y tener en ellas a la monarquía clonada en sus magistrados para impartir justicia y consolidar el poder real, en una época en la que se necesitaba un distrito pacificado y que enviara la tan necesaria plata potosina, era un argumento que Felipe II no podía desoír.

No cabe duda que los oidores charqueños también buscaban afianzar su poder e influencia. Ambas partes, el tribunal platense y la Corona, pusieron en escena un continuo intercambio de comunicaciones, donde el fin último de la información radicaba, ante todo, en el intercambio de intereses mutuos. Retomando los postulados de Arndt Brendecke, la estrategia debía basarse en hacer pasar por "objetivos" los intereses subjetivos de los actores involucrados. La información se constituyó entonces en un instrumento político. Las misivas que fluían de una a otra orilla del Atlántico, "simulaban informar sobre hechos [...] pero aspiraban a influir sobre decisiones" (Brendecke 2012: 483).

\section{Referencias Citadas}

Abecia, V.

1939 Historia de Chuquisaca. Editorial Charcas. Sucre.

Angeli, S.

2008 "Los oidores de la Audiencia de Lima en la segunda mitad del siglo XVI". Allpanchis. Revista del Instituto de Pastoral Andina 71: 77-112.

Angeli, S.

2012 “'Palabras que no fueron olvidadas': La pervivencia del discurso jurídico medieval en el alzamiento de Gonzalo Pizarro (Perú, 1544-1548)". Revista Jurídica de la Universidad Autónoma de Madrid 26: 105-122.

Angeli, S.

2013 “‘Buenos e rectos jueces?’: La visita a la Audiencia de Lima por el licenciado Briviesca de Muñatones, 15601563". Jahrbuch für Geschichte Lateinamerikas 50: 9-28.

Bakewell, P.

1988 "La maduración del gobierno del Perú en la década de 1560”. Historia Mexicana 39: 41-70.

Barriera, D.

2013 "Entre el retrato jurídico y la experiencia en el territorio. Una reflexión sobre la función distancia a partir de las normas de los Habsburgo sobre las sociabilidades locales de los oidores americanos". Caravelle 101: 133-154.
Brendecke, A.

2012 Imperio e información. Funciones del saber en el dominio colonial español. Iberoamericana Vervuert, Madrid.

Clavero, B.

1966 "Justicia y gobierno, economía y gracia". En Real Chancillería de Granada: V centenario 1505-2005, editado por David Torres Ibáñez, Javier Moya Morales y Eduardo Quesada Dorador, pp. 121-148. Diputación de Granada, Granada.

del Águila, R.

1978 [1639] Noticias Políticas de las Indias y Relación Descriptiva de la Ciudad de la Plata. Talleres de la Imprenta Universitaria. Sucre.

Garriga, C.

2006 "Patrias criollas plazas militares: sobre la América de Carlos IV". En La América de Carlos IV coordinado por Eduardo Martiré, pp. 35-130. Instituto de Investigaciones de Historia del Derecho, Buenos Aires.

Gaudin, G., Castillo Gómez, A., Gómez Gómez, M., Stumpf. R. 2017a "Introducción al dossier: Vencer la distancia, Actores y prácticas del gobierno de los imperios español y portugués". Nuevo Mundo Mundos Nuevos [En ligne]. (2 de octubre). https://journals.openedition.org/nuevomundo/71453. (28 de febrero 2020). 
Gaudin, G.

2017b El imperio de papel de Juan Díez de la Calle. Pensar y gobernar el Nuevo Mundo en el siglo XVII. Fondo de Cultura Económica. España.

Gaudin, G. y P. Ponce Leiva

2019 "Introducción al dossier: El factor distancia en la flexibilidad y el cumplimiento de la normativa en la América Ibérica". Les Cahiers de Framespa [En ligne] (30 de enero). https://journals.openedition.org/framespa/5553. (25 febrero 2020).

Gaudin, G.

2020 "Movilidad y rugosidad en la comunicación política imperial: las primeras gestiones en la Corte de los miembros de la expedición de Legazpi a Filipinas (1565-1573)". Nuevo Mundo Mundos Nuevos [En ligne]. (24 de febrero). https://journals.openedition.org/nuevomundo/79411. (28 de febrero 2020).

Geertz, C.

2003 [1973] La interpretación de las culturas. Gedisa. Barcelona.

Gil Pujol, X.

2012 "Integrar un mundo. Dinámicas de agregación y de cohesión en la Monarquía de España". En Las Indias Occidentales. Procesos de incorporación territorial a las Monarquías Ibéricas, editado por Oscar Mazín Gómez y José Javier Ruíz Ibáñez, pp. 69-108. El Colegio de MéxicoRed Columnaria. México.

Goldwert, M.

1956 "La lucha por la perpetuidad de las encomiendas en el Perú virreinal”. Revista Histórica 1956: 336-360.

Gómez Gómez, M.

2008 El Sello y registro en Indias: imagen y representación. Böhlau, Colonia.

Herrero Sánchez, M.

2017 "El modelo republicano en una monarquía de ciudades". En Soulevements, Révoltes, Révolutions. Dans l'empire des Habsbourg d'Espagne, XVI ${ }^{e}$-XVII $I^{e}$ siècle, editado por Alain Hugon y Alexandra Merle, pp. 245-266. Colección Casa de Velázquez. Madrid. https://books.openedition.org/ cvz/1906?lang=es. (2 de marzo de 2020).

Hespanha, A. M.

1993 La gracia del Derecho: Economía de la cultura en la Edad Moderna. Centro de Estudios Constitucionales. Madrid.

Levillier, R.

1918 La Audiencia de Charcas. Correspondencia de presientes y oidores. Biblioteca del Congreso Argentino, Madrid.

Lohmann Villena, G.

1977 Las ideas jurídico-políticas en la Rebelión de Gonzalo Pizarro. Casa-Museo de Colón y Seminario Americanista, Secretaría de Publicaciones Universidad de Valladolid. Valladolid.

Mendoza Loza, G.

1938 "Año en que fue fundada la Villa del Plata". En Revista de la Universidad Mayor, Real y Pontificia de San Francisco Xavier de Chuquisaca 1938: 86-122.

Presta, A. M.

2010 "Desde la Plaza a los Barrios. Pinceladas étnicas tras las casas y las cosas. Españoles e indios en la ciudad de La Plata, Charcas 1540-1562". Nuevo Mundo Mundos Nuevos [En Ligne]. (10 enero 2010). https://journals.openedition. org/nuevomundo/58926. (20 de febrero 2020).

Recopilación de Leyes de los Reinos de las Indias

1998 [1680] Imprenta Nacional del Boletín Oficial del Estado. Madrid.

Rodríguez Rivero, $\mathrm{M}$.

2011 La edad de oro de los virreyes. Akal. Madrid.

Tau Anzoátegui, V.

1997 Nuevos Horizontes en el estudio del Derecho Indiano. Instituto de Investigaciones de Historia del Derecho. Buenos Aires. 